13,14

\title{
Влияние толщины субмикронных пленок электроактивных полимеров на токи термостимулированной деполяризации
}

\author{
() Д.Д. Карамов ${ }^{1}$, В.Х. Ильясов ${ }^{2}$, А.Н. Лачинов ${ }^{1}$, А.Ф. Галиев ${ }^{1}$, А.А. Лачинов ${ }^{1}$ \\ ${ }^{1}$ Институт фризики молекул и кристаллов УФИЦ РАН, \\ Уфа, Россия \\ ${ }^{2}$ Ухтинский государственный технический университет, \\ Ухта, Россия \\ E-mail: karamov_danfis@b
}

Поступила в Редакцию 5 марта 2020 г.

В окончательной редакции 5 марта 2020 г.

Принята к публикации 9 апреля 2020 г.

Представлены результаты исследования токов термостимулированной деполяризации тонких пленок полидифениленфталида (ПДФ) толщиной от $20 \mathrm{~nm}$ до $1.4 \mu \mathrm{m}$ в режиме „постоянной напряженности“ в структуре с изолирующей диэлектрической прослойкой. Обнаружен немонотонный характер зависимости энергии активации центров захвата носителей заряда и релаксации объемного заряда от толщины полимерных пленок ПДФ. Установлена корреляция между изменением надмолекулярной структуры пленок и указанных параметров. Интерпретация полученных результатов проводится с привлечением теории термостимулированной релаксации заряда в короткозамкнутых гетерогенных структурах.

Ключевые слова: термостимулированные токи деполяризации, тонкие полимерные пленки, надмолекулярная структура, полидифениленфталид, электроактивные полимеры.

DOI: 10.21883/FTT.2020.08.49619.067

\section{1. Введение}

Высокий спрос на материалы „умной“ электроники привел к синтезу широкого спектра полимеров с уникальными функциональными свойствами. Созданы целые классы полимеров способных изменять свои электрофизические характеристики при малых внешних воздействиях (изменение давления, освещенности, влажности, состава атмосферы, электрических и магнитных полей, радиации и т.д.). К таким материалам можно отнести термостойкие несопряженные полимеры класса полиариленфталидов (ПАФ) [1,2]. Субмикронные пленки ПАФ, демонстрируют аномально высокие уровни электропроводности, сопоставимые с электропроводностью металлов. Объяснение уникальных электрофизических свойств тонких полимерных пленок связано с механизмом делокализации глубоких электронных состояний в запрещенной зоне полимера, при достижении концентрации избыточного заряда определенной величины [1]. При этом, одной из особенностей данного класса полимеров является сложный спектр электронных состояний в запрещенной зоне [3-5]. Как правило, характер распределения этих состояний обусловлен химическим строением конкретного полимера [6].

В работах $[7,8]$ было установлено, что надмолекулярное упорядочение в тонких пленках одного из представителей ПАФ - полидифениленфталида (ПДФ) изменяется при изменении толщины пленки. Позднее $[9,10]$ было показано, что в переходной области толщин происходит изменение некоторых электронных свойств тонких пленок. Это, в принципе, не противоречит общим представлениям о взаимосвязи структуры и свойств полимерных материалов. Например, в [11] исследования процессов релаксации в пленках полиимида R-BAPS показали, что на энергию активации центров захвата носителей заряда влияет не только химическое строение полимера, но и надмолекулярная структура исследуемых объектов [12]. Аналогичная взаимосвязь прослеживается и в других электронных свойствах различных полимеров [13,14].

В работах [7,8] было установлено, что в диапазоне толщин от 100 до $200 \mathrm{~nm}$ надмолекулярное упорядочение полимерных пленок ПДФ претерпевает изменение от однородного глобулярного до структур с относительно крупными агрегатами макромолекул. Характер этих изменений может быть важен при прогнозировании электронных свойств различных гетероструктур создаваемых на основе широкозонных полимеров. Однако до сих пор связь между надмолекулярной структурой пленок ПДФ и изменением энергетического распределения ловушек заряда не была изучена.

В связи с этим, целью работы явилось изучение энергетических характеристик ловушек (энергии активации) в зависимости от толщины полимерных пленок ПДФ методом термостимулированной токовой спектроскопии [15].

\section{2. Объект и методы исследования}

Объектом исследования были выбраны тонкие пленки полидифениленфталида, так как ранее на таких объектах проводилось изучение ловушечных состояний термостимулированными методами [3-6,16,17]. А также была исследована надмолекулярная структура тон- 
ких пленок различными методами. Экспериментальные образцы формировались на стеклянной подложке и представляли собой многослойную систему вида металл/полимер/металл. Методом термодиффузионного напыления формировался нижний алюминиевый электрод. Второй медный электрод был прижимным. Давление электрода на образец выбиралось из двух соображений: оно должно было быть меньше порога электронного переключения пленки по давлению [1] и в тоже время обеспечивать надежный электрический контакт. Качество контакта оценивалось по виду и воспроизводимости вольт-амперных характеристик $(\mathrm{BAX})$. Полимерная пленка наносилась на металлический электрод методом центрифугирования (3000 rpm) из раствора ПДФ в циклогексаноне. Толщина полимерных пленок задавалась путем изменения концентрации растворов в пределах от 0.5 до $10 \mathrm{wt} . \%$. Это соответствовало толщинам пленок от $20 \mathrm{~nm}$ до $1.4 \mu \mathrm{m}$. Сушка образцов производилась в течение $30 \mathrm{~min}$ при нормальных условиях, далее в сушильном шкафу в течение $40 \mathrm{~min}$ при температуре $150^{\circ} \mathrm{C}$ - для удаления остатков растворителя. Контроль качества и толщины полимерных пленок проводили методами атомносиловой микроскопии с помощью микроскопа СММ2000T. Зависимость толщины полимерных пленок от концентрации раствора полимера и среднеквадратичная шероховатость поверхности полимерных пленок представлены на рис. 1.

В качестве основного метода исследования был выбран метод термостимулированных токов деполяризации (ТСД). Этот метод относят к высокочувствительным методам исследования электронных состояний в полимерных материалах. Он используется для изучения механизмов электрической релаксации и энергетических параметров электрически активных центров захвата заряда в диэлектриках и полупроводниках [15]. Ранее исследование спектров токов ТСД в микронных пленках ПДФ [16,17] позволило выявить некоторые механизмы ответственные за термическую релаксацию центров захвата. Было установлено, что основными механизмами релаксации заряда выступают дипольная поляризация, связанная с тепловым движением боковых фталидных фрагментов, и изменение концентрации объемного заряда за счет захвата электронными ловушками инжектированных из электродов зарядов.

Сложность в реализации данного метода связана с возможностью возникновения в тонких пленках ПДФ зарядовой неустойчивости, приводящей к переключению проводимости образца в состояние с высокой проводимостью. Ранее [1,18-20] было установлено, что субмикронные пленки ПДФ, помещенные между двух металлических электродов, при относительно небольших приложенных напряжениях, способны изменять свою проводимость на несколько порядков, вплоть до проводимости металлов. Очевидно, что возможное увеличение проводимости тонких полимерных пленок в результате инжекции зарядов из электродов в электрическом поле может существенно ограничить применимость термостимулированного метода. В связи с этим, для исключения возникновения равновесной проводимости ультратонких пленок полимера была создана гетерогенная двухслойная структура с изолирующей диэлектрической прослойкой по аналогии с [15]. При таком подходе изолирующий слой должен обладать низкой проводимостью и иметь большую толщину по сравнению с исследуемой пленкой.

Подобная структура позволяет накапливать заряды, обусловленные поляризацией Максвелла-Вагнера, на межфазных границах полимер-изолятор и в объеме тонкой полимерной пленки. В этом случае выражение для тока термостимулированной деполяризации $j(T)$ в двуслойной гетероструктуре, с учетом проводимости слоев будет иметь вид [15]:

$$
j(T) \approx \frac{\varepsilon_{2}^{2} d_{1} U_{b} \lambda_{1}}{\varepsilon_{1}^{2} d_{2}} \exp \left[-\frac{E_{a 1}}{k T}-\int_{T_{0}}^{T} \frac{\omega_{1}}{\beta} \exp \left(-\frac{E_{a 1}}{k T^{\prime}}\right) d T^{\prime}\right],
$$

где $\varepsilon_{1}, \varepsilon_{2}$ - диэлектрические проницаемости полимерной пленки и изолирующей прослойки, $d_{1}, d_{2}-$ соответ-
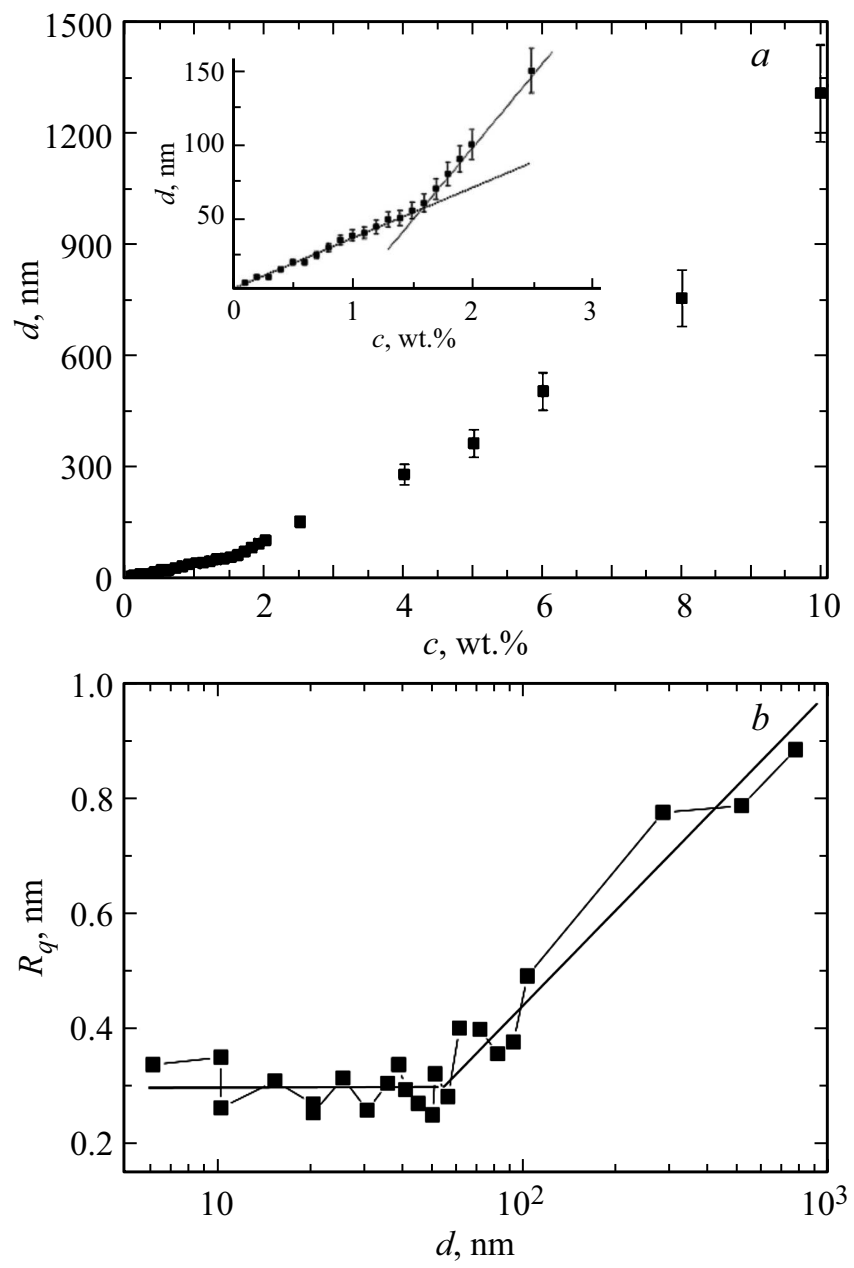

Рис. 1. График зависимости толщины полимерной пленки от концентрации раствора с $(a)$ [8] и среднеквадратичная шероховатость $R_{q}$ субмикронных пленок $(b)$. 


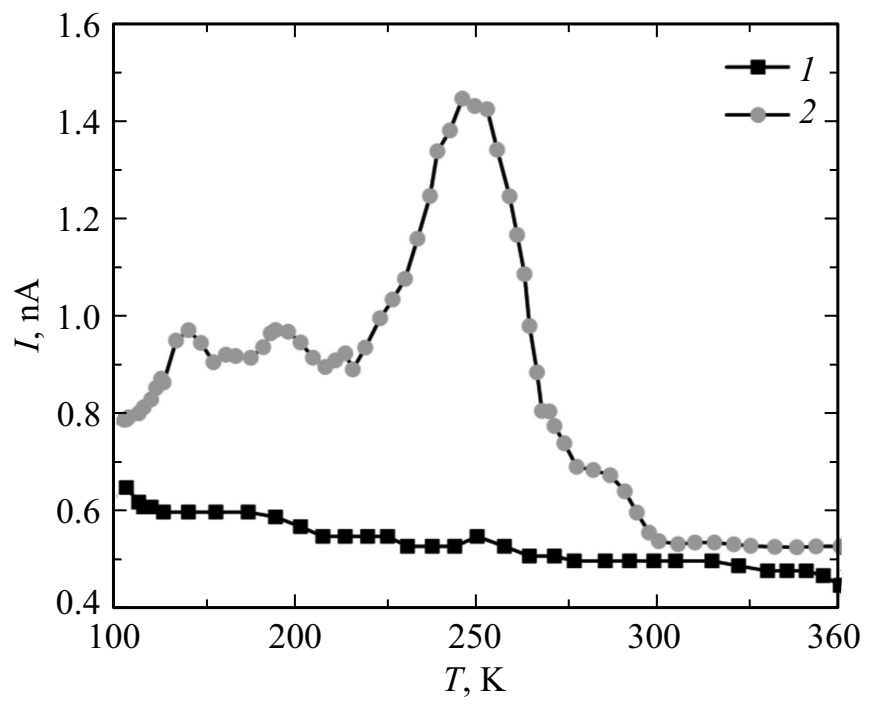

Pис. 2. Спектр токов ТСД для пленок фторопласта (1) и ПДФ толщиной $20 \mathrm{~nm}(2)$ в структуре с изолирующей прослойкой фторопласта. Скорость нагрева $3 \mathrm{~K} / \mathrm{min}$.

ственно их толщины, $U_{b}$ - напряжение поляризующего поля, $\lambda_{1}, E_{a 1}, \omega_{1}-$ проводимость, энергия активации и частотный фактор полимерной пленки, $T$ и $T_{1}-$ текущая и начальная температуры.

Анализ зависимости (1) позволяет сделать заключение, что форма спектра токов ТСД будет определяться параметрами исследуемой полимерной пленки, в нашем случае пленки ПДФ, но не свойствами изолирующей прослойки.

В связи с этим, в качестве изолирующей прослойки была выбрана тонкая пленка фторопласта Ф-4 толщиной $d_{2}=10 \mu \mathrm{m}$, которая располагалась между полимерной пленкой и верхним прижимным электродом.

Для подтверждения сделанного выше утверждения (1), были проведены контрольные измерения токов ТСД указанной пленки фторопласта и двуслойной пленки содержащей фторопласт и ПДФ (рис. 2). Было установлено, что в заданных условиях реализации измерений особенностей в спектре ТСД фторопласта не регистрируется (рис. 2). При этом двуслойная пленка демонстрирует достаточно типичный для ПДФ спектр [17]. Сравнительный анализ полученных экспериментальных данных подтверждает выводы, вытекающие из уравнения (1). В частности, пленка фторопласта толщиной $d_{2}$ значительно превышающей толщину пленки ПДФ $d_{1}$ и проводимостью меньшей проводимости ПДФ не оказывает влияния на положение температурных максимумов и форму спектров ТСД. Удельное объемное сопротивление фторопласта $\sim 10^{17} \Omega \cdot \mathrm{cm}$, а ПДФ $\sim 10^{12} \Omega \cdot \mathrm{cm}[21]$.

Энергии активации $E_{a}$ были оценены методом положения температурного пика [9]. Для расчета энергии активации по положению температурного пика, приме- нена формула

$$
E_{a}=\frac{k T_{m}^{2} I_{m}}{\sigma\left(T_{m}\right) \beta}
$$

где $k$ - коэффициент Больцмана, $I_{m}-$ максимальный ток соответствующего пика в спектре ТСД, $T_{m}$ - температура максимума соответствующего пика тока ТСД, $\sigma\left(T_{m}\right)$ - заряд, высвобожденный в процессе релаксации, $\beta$ - скорость нагревания.

\section{3. Результаты и обсуждения}

Спектры токов ТСД для пленок ПДФ (толщины от $20 \mathrm{~nm}$ до $1.4 \mu \mathrm{m})$ с изолирующим слоем фторопласта представлены на рис. 3 .

Для каждого спектра токов ТСД выделены две области - низкотемпературная (от 230 до $270 \mathrm{~K}$ ) и высокотемпературная (от 270 до $310 \mathrm{~K}$ ). Первая область, согласно [6,17] соответствует дипольной поляризации, вторая - формированию заряда, захваченного на ловушках в объеме полимерной пленки.

На рис. 4 приведены экспериментально полученные зависимости температурного положения пиков и максимума тока от толщины полимерной пленки для 1-ой и 2-ой температурной области выделенных на спектрах ТСД. Как известно [15], амплитуда пиков тока термостимулированной деполяризации обычно пропорциональна концентрации носителей заряда, захваченных на ловушки при заряжении диэлектрика, а величина заряда прямо пропорциональна напряжению приложенного поля и емкости образца. Однако, в эксперименте наблюдается сложный характер изменения величины пиков тока ТСД, как от толщины полимерной пленки, так и изменения температурного положения максимумов

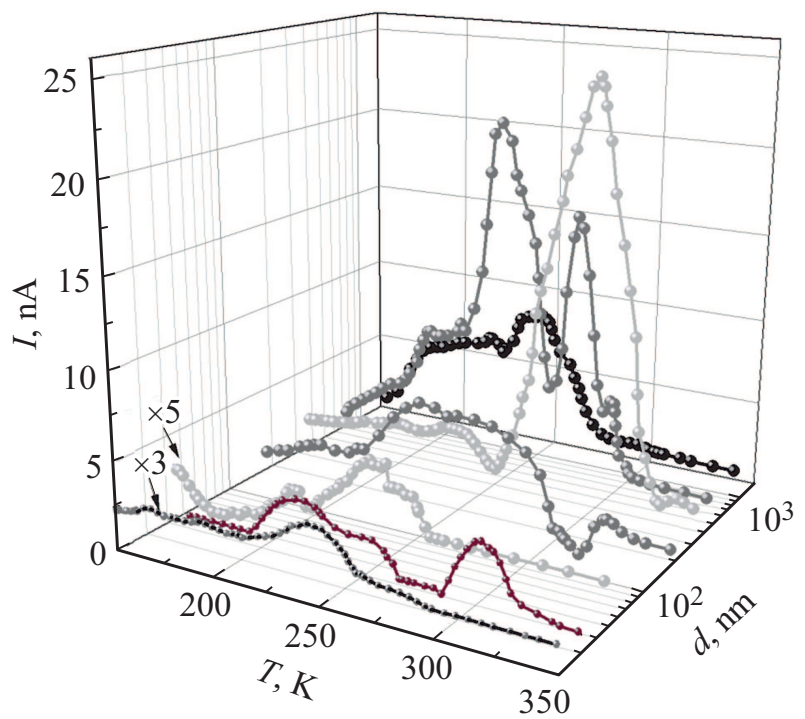

Pис. 3. Спектр токов ТСД для пленок ПДФ в структуре с изолирующей прослойкой фторопласта. Скорость изменения температуры $3 \mathrm{~K} / \mathrm{min}$. 

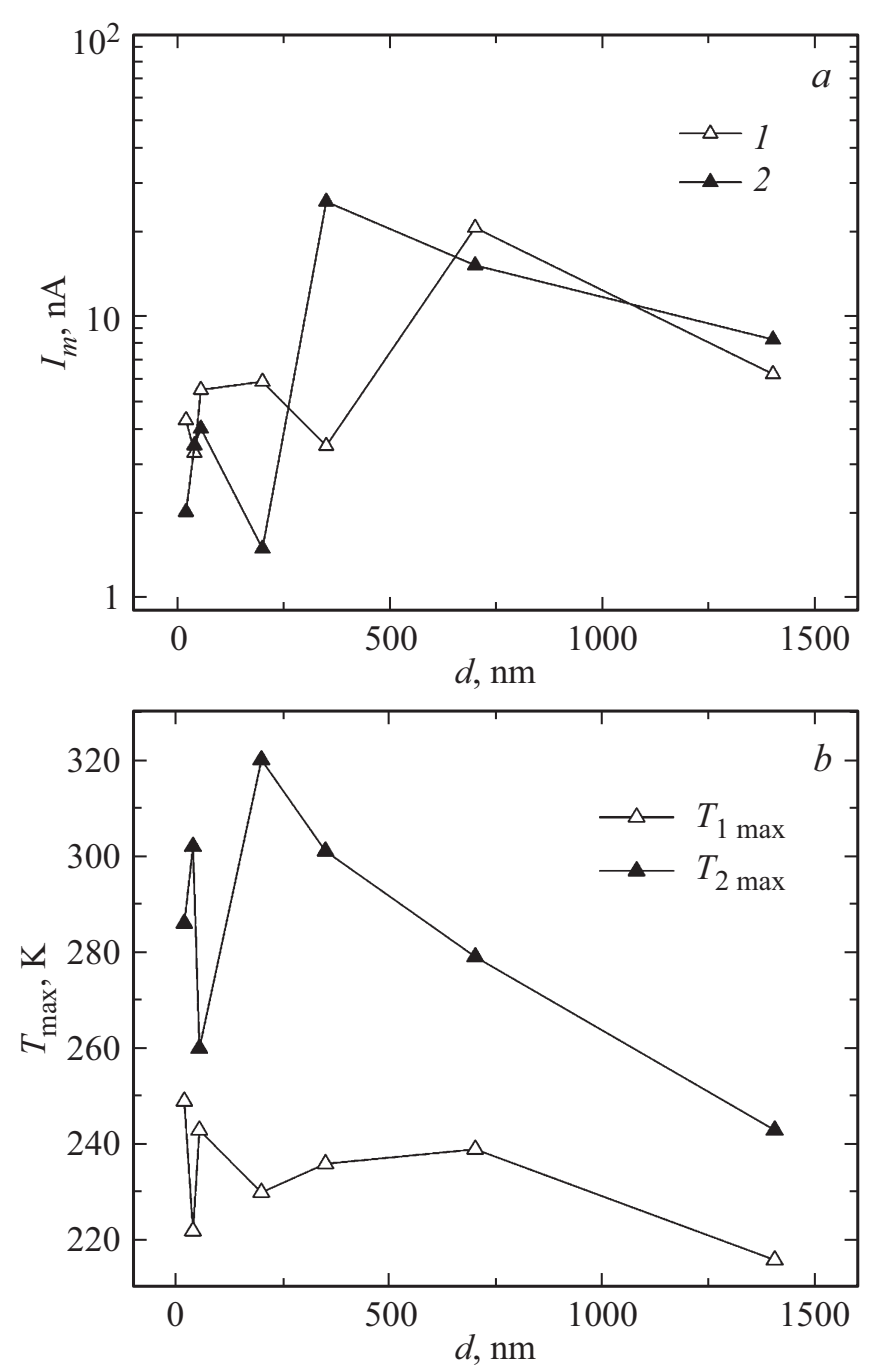

Рис. 4. Зависимость температурного положения пиков $(a)$ и максимума тока $(b)$ от толщины полимерной пленки для 1 и 2 температурной области спектров ТСД.

тока деполяризации до толщин $\sim 200 \mathrm{~nm}$. По мере увеличения толщины полимерной пленки от $200 \mathrm{~nm}$ и выше, $T_{m}$ линеаризуется и смещается в область меньших температур.

Связь температурного положения максимума тока ТСД $\left(T_{m}\right)$ с параметрами центров захвата и условиями эксперимента, определяется из уравнения (1) путем исследования ее на экстремум

$$
\frac{E_{a 1}}{k T_{m}^{2}}=\frac{\omega_{1}}{\beta} \exp \left(-\frac{E_{a 1}}{k T_{m}}\right) .
$$

Таким образом, на изменение положения температурного пика в зависимости от толщины полимерной пленки может влиять как изменение энергетического спектра центров захвата заряда, так и эффективный частотный фактор.

Используя известные приближенные формулы, примененные в работе [16], можно определить максимум тока ТСД

$$
I_{m} \sim A \frac{d_{1} \lambda_{1}}{\varepsilon_{1}^{2}} \frac{E_{a 1}}{k T_{m}^{2} \omega_{1}},
$$

где $A-$ постоянные параметры, не зависящие от свойств исследуемой полимерной пленки.

Из соотношения (4) можно оценить изменение экспериментальных данных в зависимости от толщины полимерной пленки:

$$
I_{m} T_{m}^{2} \sim A \frac{\lambda_{1}}{\varepsilon_{1}^{2}} \frac{E_{a 1}}{k \omega_{1}} d_{1} .
$$

При слабой (несущественной) зависимости энергетических параметров от толщины пленок, должно выполняться соотношение $I_{m} T_{m}^{2}=B d_{1}+C$, где $B-$ характеризует изменение электрофизических и энергетических параметров пленки ПДФ, $C$ - некоторый коэффициент.

На рис. 5 приведены экспериментальные данные, которые в пределах погрешности линеаризуются 2-мя кривыми с разными углами наклона. Переход угла наклона происходит в области толщин близких к $200 \mathrm{~nm}$. В этой области толщин согласно $[7,8]$ происходит изменение надмолекулярного строения пленок ПДФ. Таким образом, можно утверждать, что на энергетические параметры существенным образом влияет изменение надмолекулярной структуры тонких пленок.

Зависимость энергий активаций центров захвата от толщины полимерной пленки, рассчитанная из экспериментальных данных по формуле (2), представлена на рис. 6. Вид кривой энергий активаций имеет нелинейную зависимость. На графике выделяются три участка.

Первый диапазон толщин до $60 \mathrm{~nm}$, в котором наблюдается увеличение значений энергий активации для обеих областей. Причем значение энергий активаций для первой области больше, чем для второй.

На втором и третьем диапазоне толщин энергия активации для второй области больше, чем для первой.

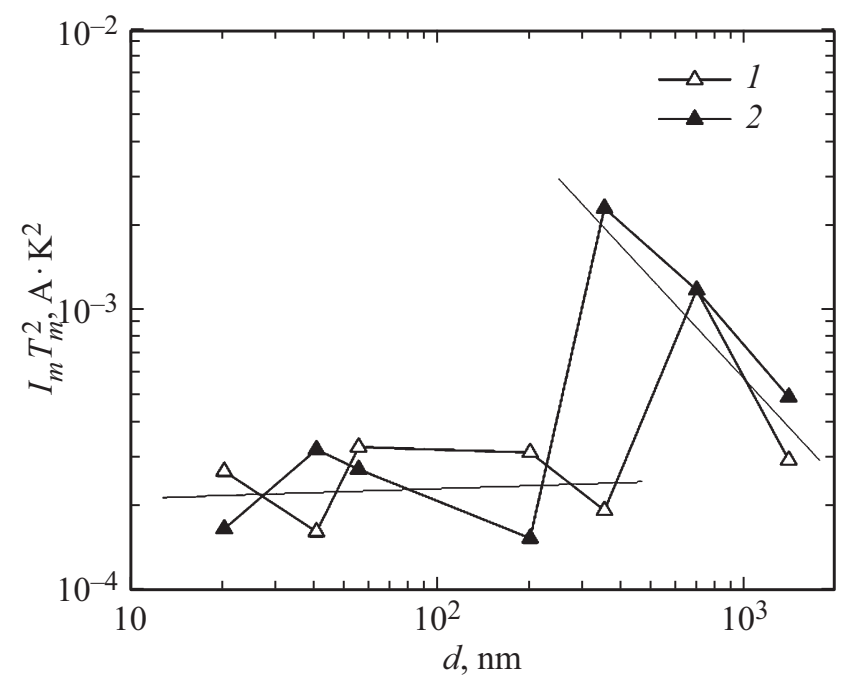

Рис. 5. Зависимость величины $I_{m} T_{m}^{2}$ от толщины пленки ПДФ для 1 и 2 температурной области спектров ТСД. 


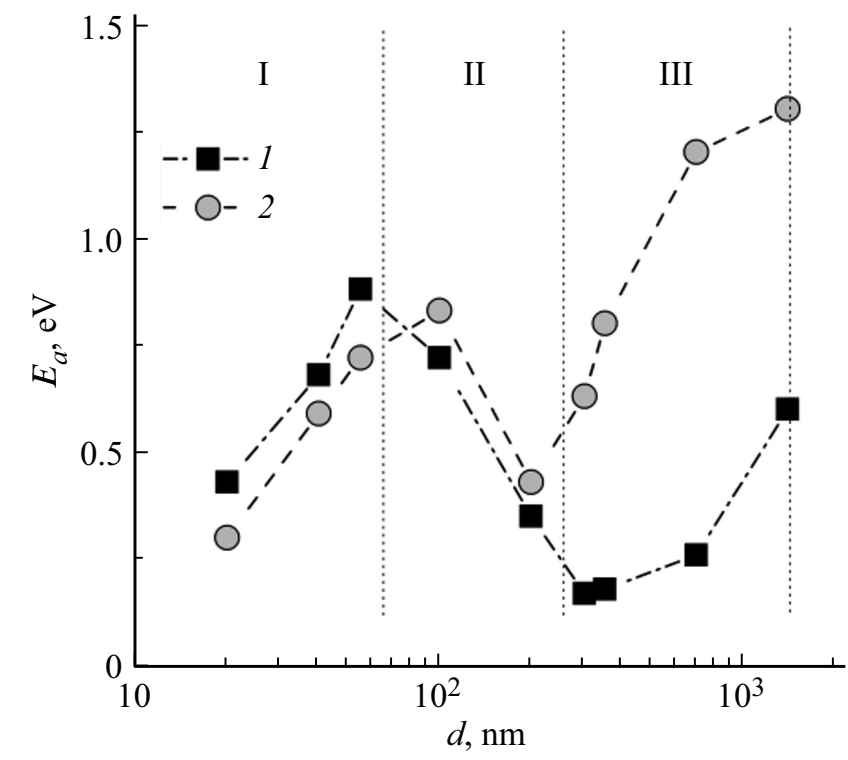

Рис. 6. График зависимости энергии активации от толщины полимерной пленки для 1 и 2 температурной области спектров ТСД.

Причем до $200 \mathrm{~nm}$ наблюдается спад значений энергий активации. Далее, с увеличением толщины полимерной пленки, энергии активации увеличиваются, при этом разница энергий активации между дипольной поляризацией и становится более выраженными (значительными).

В работах $[7,8]$ представлены результаты экспериментальных исследований надмолекулярной структуры полимерных слоев субмикронных пленок полидифениленфталида методами атомно-силовой микроскопии и малоуглового рассеяния нейтронов. Установлено, что полимерные пленки в зависимости от изменения реологических свойств раствора, используемой при их изготовлении, образуют два вида надмолекулярной структуры в объеме материала - глобулярная структура и структура в виде ассоциатов в форме эллипсоидов. Переход от одной надмолекулярной структуры к другой представлен на рис. 6.

Первая надмолекулярная организация соответствует толщинам до $60 \mathrm{~nm}$ (рис. 6). Этой области толщин соответствует минимальная шероховатость полимерных пленок, проявление однородной спонтанной поверхностной поляризации и обратимого полного переключения поляризации, инициируемое внешним полем [9,10]. Наблюдаемые явления соответствуют первому участку в зависимости энергий активации от толщины полимерной пленки. Большая величина энергии активации дипольной поляризации относительно высвобождения объемного заряда возможно связано с ориентирующим действием поверхности подложки на сверхтонкие слои полимерной пленки.

Второй диапазон - участок графика от 60 до $200 \mathrm{~nm}$ (рис. 6) на зависимости энергии активации от толщины, связан с перестройкой надмолекулярной структуры полимерной пленки, что приводит к увеличению дефектности структуры пленки и уменьшению значений энергий активации. Все это приводит к уменьшению влияния подложки на дипольную поляризацию, а также возникновению более мелких электронных ловушек для „связанного“ объемного заряда.

В третьем диапазоне толщин (рис. 6) происходит увеличение энергий активации. Эта область соответствует формированию ассоциатов макромолекул в объеме полимерной пленки. Появление ассоциатов макромолекул приводит к изменению условий поляризации и, соответственно, влияет на процесс термической релаксации поляризованных молекул. При этом происходит резкое увеличение 2-ой высокотемпературной области значений энергий активаций, соответствующих процессу формирования объемного заряда, захваченного на электронные ловушки, с тенденцией к насыщению значения энергии активации в пределах $1.2 \pm 0.1 \mathrm{eV}$.

\section{4. Заключение}

Существует точка зрения [16], что энергия активации слабо зависит от толщины полимерной пленки. В связи с этим, обращает на себя внимание наличие трех участков на зависимости энергии активации от толщины (рис. 6), которые изменяются в пределах $1.5 \mathrm{eV}$ : от 0.17 до $0.88 \mathrm{eV}$ для 1 области; от 0.3 до $1.3 \mathrm{eV}$ для 2 области в выбранном диапазоне толщин. В данном случае эти участки коррелируют со структурными исследованиями полимерных пленок [7,8]. Использованный в работе метод токов термостимулированной деполяризации позволил выявить область критических толщин до $200 \mathrm{~nm}$, которые требуют более детального исследования. Возможно, что в данной области полимерных пленок могут быть обнаружены новые свойства.

\section{Финансирование работы}

Работа выполнены в рамках государственного задания № АААА-А19-119022290052-9, при поддержке гранта „Развитие сети ЦКП Российской Федерации“ № 075-15-2019-1651.

\section{Конфликт интересов}

Авторы заявляют, что у них нет конфликта интересов.

\section{Список литературы}

[1] А.Н. Лачинов, Н.В. Воробьева. УФН 176, 1249 (2006).

[2] С.Н. Салазкин, В.В. Шапошникова, Л.Н. Мачуленко, Н.Г. Гилева, В.А. Крайкин, А.Н. Лачинов. Высокомолекулярн. соединения А 50, 399 (2008).

[3] А.С. Накаряков, В.А. Антипин, А.Н. Лачинов, Д.А. Мамыкин, А.Ф. Пономарев. Химия высоких энергий 46, 503 (2012). 
[4] А.С. Накаряков, А.Н. Лачинов, А.Ф. Пономарев, Е.Е. Цеплин, В.А. Антипин. ФТТ 53, 2397 (2011).

[5] В.Х. Ильясов, А.Н. Лачинов, А.В. Мошелев, А.Ф. Пономарев. ФТТ 50, 547 (2008).

[6] А.Ф. Пономарев, А.В. Мошелев, В.Х. Ильясов, А.Н. Лачинов, В.М. Корнилов, С.Н. Салазкин, В.В. Шапошникова, Д.С. Шарапов, А.О. Буракова, Н.В. Улитин. Вестн. КТУ 17, 159 (2014).

[7] В.М. Корнилов, А.Н. Лачинов, Д.Д. Карамов, И.Р. Набиуллин, Ю.В. Кульвелис. ФТТ 58, 1030 (2016).

[8] Д.Д. Карамов, В.М. Корнилов, А.Н. Лачинов, В.А. Крайкин, И.А. Ионова. ЖТФ 86, 124 (2016).

[9] Р.М. Гадиев, А.Н. Лачинов, Д.Д. Карамов, Д.А. Киселев, В.М. Корнилов. ЖЭТФ 150, 168 (2016).

[10] D.D. Karamov, D.A. Kiselev, M.D. Malinkovich, V.M. Kornilov, A.N. Lachinov, R.M. Gadiev. Rus. Microelectron. 45, 619 (2016).

[11] M.E. Borisova, A.L. Didenko, A.M. Kamalov, V.E. Smirnova, V.E. Yudin. Polymer Sci. A 60, 751 (2018).

[12] В.А. Закревский, В.А. Пахотин. Высокомолекулярн. соединения А 23, 658 (1981).

[13] B.G. Kim, E.J. Jeong, J.W. Chung, S. Seo, B. Koo, J. Kim. Nature Mater. 12, 659 (2013).

[14] Е.Л. Александрова, М.Е. Компан, М.М. Дудкина, А.В. Теньковцев, Е.И. Теруков. ФТП 38, 1110 (2004).

[15] Ю.А. Гороховатский, Г.А. Бордовский. Термоактивационная токовая спектроскопия высокоомных полупроводников и диэлектриков. Наука, М. (1991). 248 с.

[16] Ю.А. Гороховатский, Д.Д. Карамов, Ю.Ж. Мусралиева, А.Ф. Пономарев. Изв. РГПУ им. А.И. Герцена 157, 60 (2013).

[17] А.Н. Лачинов, В.Х. Ильясов, А.Ф. Пономарев. Хим. физика 28. 78 (2009).

[18] V.R. Nikitenko, A.R. Tameev, A.V. Vannikov, A.N. Lachinov, H. Bässler. Appl. Phys. Lett. 92.138 (2008).

[19] И.Р. Набиуллин, А.Н. Лачинов, А.Ф. Пономарев. ФТТ 54, 230 (2012).

[20] А.Н. Лачинов, В.М. Корнилов, Т.Г. Загуренко, А.Ю. Жеребов. ЖЭТФ 129, 728 (2006).

[21] A.N. Lachinov, A.Yu. Zherebov, M.G. Zolotukhin. Synth. Met. 59, 377 (1993).

Редактор К.В. Емцев 